\title{
Cocoa Farming and Difficulties in Adopting the Innovations of Intensive Agriculture in Boguedia (Ivory Coast)
}

\author{
Akmel Meless Siméon*, Dibi Djibli Vincent, Blegui Guédé Bayard \\ Départment of Anthropology and Sociology, University of Alassane Ouattara, Bouake, Ivory Coast \\ Email address: \\ melessovsky65@gmail.com (A. M. Siméon),vincentdibi@gmail.com (D. D. Vincent), bayardblegui@gmail.com (B. G. Bayard) \\ ${ }^{*}$ Corresponding author
}

\section{To cite this article:}

Akmel Meless Siméon, Dibi Djibli Vincent, Blegui Guédé Bayard. Cocoa Farming and Difficulties in Adopting the Innovations of Intensive Agriculture in Boguedia (Ivory Coast). American Journal of Agriculture and Forestry. Vol. 7, No. 5, 2019, pp. 177-184.

doi: 10.11648/j.ajaf.20190705.13

Received: March 21, 2019; Accepted: April 29, 2019; Published: September 3, 2019

\begin{abstract}
The Ivorian economy is essentially based on agriculture, especially the coffee-cocoa duo. The country experienced growth in the 1970s, perceived by specialists as the "Ivorian miracle". But this euphoria turned into "an economic mirage", because of certain factors including the aging of plants, the slowdown in cocoa production. Faced with this situation, strategies are being developed by the National Center for Agronomic Research to significantly improve productivity. But they meet resistance. The objective of this research is to analyze cocoa farming and the difficulties related to the adoption of agricultural innovations. To achieve this, we selected Boguedia, a town located in Upper Sassandra, a field of investigation, because of intensive agriculture. This socio-anthropological research is both qualitative and quantitative. It is based on techniques (observation, focus group, registers) and data collection tools (interview guide, questionnaire). The research describes cocoa farming and shows its socio-economic value. It also analyzes the causes of the resistance of Boguedia populations to agricultural innovations. This situation of discomfort needs a critical analysis of the agricultural innovation policy.
\end{abstract}

Keywords: Cocoa Farming, Intensive Farming, Socioeconomic Value, Innovation, Critical Analysis, Ivory Coast

\section{Introduction}

Since independence, agriculture has been the mainstay of the sub-Saharan economy and even the basis of its economy. From Mali to Senegal via Guinea, Burkina Faso, etc., the situation is the same. The activities concerned the production, and export of agricultural products, from Africa to Europe, the first trading partner [1]. Ivory Coast, agricultural country is not spared. Since 1960, the date of its accession to national sovereignty, it became involved in the cocoa economy, which made it the flagship country of the sub-region (West Africa) in the 1970s. This culture has long been the main export product. With fluctuating world market prices, cocoa prices have fallen, making producers "cancerous economically". Faced with the slump of the product, the rulers have diversified cultures. Thus, populations have converted to rubber growing. Today, we are witnessing in the forest area of the country, a real craze for the cultivation of rubber trees in the peasants [2]. This situation led to the rapid increase in natural rubber production (from 82 tons 433 in 1961 to 108600 tons in 1998). It reached 178000 tons in 2006, or $1.8 \%$ of tons worldwide. Climate change with low rainfall in places, diseases to which people are exposed, the "swollenshoot" virus, which has officially affected $6 \%$ to $8 \%$ of Ivorian cocoa trees, conflictual relations between farmers and stakeholders development, negatively influenced production. Faced with this worrying situation, the political authorities have developed strategies to modernize cocoa farming and improve productivity. These are agricultural innovations (irrigation, mechanization, etc.). However, these provisions have not been able to achieve the desired results, in several localities in Côte d'Ivoire, because of the aforementioned socio-economic and environmental obstacles [3]. The city of Boguedia is not spared. The locality, particularly forest area is facing the same situation. Il is interested in research for several reasons:

(1) Cocoa farming is a source of wealth in Boguedia. This activity is essential for the population, since the work 
provides substantial income for producers. Out of 100 people interviewed, 25 individuals reach between $1300000 \mathrm{FCFA}$ and $1800000 \mathrm{FCFA} ; 18$ people earn about 1600000FCFA and 2000000FCFA; when 9 people receive more than 2000000FCFA a year. These incomes intervene in the satisfaction of social needs (food, housing, clothing, health);

(2) Retency to agricultural innovations. In Boguedia, cocoa farmers have difficulty applying new strategies to their plantations for various reasons (poverty, communication problems, health problems, etc.);

(3) The deconstruction of agricultural policy. Producers think they are marginalized because they are not involved in decision-making related to new farming strategies. Also they are exposed to diseases in the work. The existence of situations of discomfort requires a critical analysis of the provisions concerning modernization and productivity in cocoa farming, especially in Boguedia. From these observations follows a series of questions, the main one being: «Why are the peasants of Boguedia, who are engaged in cocoa farming, reluctant to agricultural innovations»?? To this question are attached secondary questions: "What are the factors that justify the cocoa exploitation in this locality»? «What are the obstacles to farmers adopting agricultural innovations»? «How can the deconstruction of agricultural policy promote the adoption of innovations in cocoa farming»? The objective of this research is to analyze cocoa farming, the difficulties related to the adoption of innovations and to propose solutions, with a view to the populations' adherence to new agricultural strategies in Boguedia. The thesis is: "Cocoa farming is a source of wealth for the people. Despite this importance, farmers are reluctant to agricultural innovations because of socio-economic and environmental problems. This situation requires a re-reading of agricultural policy in cocoa farming».

\section{Method}

\subsection{Investigation Site}

It is the city of Boguedia. It is located in the region of Haut Sassandra in Ivory Coast. Boguedia is located 30 kilometers from Daloa and 15 kilometers from Issia on the axis connecting these two cities. The neighboring cities are: Daloa, Issia and Saioua. Its population is estimated at 20943 inhabitants (11396 men and 9547 women), according to the general census of the population and the habitat of 2014 .

\subsection{Data Collection Technique and Theories of Analysis}

The choice of this locality is linked to the craze of farmers for cocoa farming. It is a source of wealth for the population. In short, the activity provides substantial income for producers. It is also justified by the reluctance of cocoa farmers to agricultural innovations. The respondents are selected according to criteria including the availability, the practice of cocoa farming, knowledge of the problems related to the adoption of innovations. We opted for a reasoned choice, since it is a matter of targeting resource persons who can better educate us. 3843 cocoa farmers were counted. Unable to interview the entire target population, we decided to retain 100 people, men and women including illiterates. Also, those with secondary and higher education were selected. The focus group, the observation, the registers and the questionnaire are mobilized for the collection of information. The deepening of the results necessitated the mobilization of theories including functionalism [4] to justify the socioeconomic value of cocoa farming. The theory of resilience allowed farmers to overcome poverty by investing in the activity [5]. Through conflict theory [6], we have grasped the conflicting relations between peasants, trainers and cooperatives. Stakeholder theory [7] has helped to understand how the different actors are brought into agreement during the conflict. As for human capital [8], it has made it possible to explain the reluctance of peasants to innovations. She also helped to understand why some farmers do not know where cocoa comes from. The research has three parts. The first describes cocoa farming and analyzes its socio-economic value. The second part explains the difficulties related to the adoption of agricultural innovations among farmers in Boguedia. The third is an outline of solutions, to facilitate the adoption of new agricultural strategies in the locality.

The methodological approach yielded the following results:

\section{Result}

\subsection{Cocoa Farming, an Essential Activity}

The information gathered in Boguedia from the resource persons from the focus group and the questionnaire was analyzed. To achieve this, we asked the cocoa farming survey: "What do you know about cocoa farming in Côte d'Ivoire"? Here are some of the answers:

Cocoa farming is linked to slave trade or trade. So it's an activity that existed before the colonial period. However, it has been flourishing with oil palm cultivation, during the colonial period to support Europe's sluggish economy, because of world wars. Today, cocoa farming is the country's main source of wealth (A. L, 38 years old, student; G. S, 29 years old, studient).

Cocoa cultivation started here at home years ago. At first it was difficult, because you had to work with your hand, with a machete and an ax. Today, things have changed, because there are chainsaws to cut down the trees and clean the plot. Cocoa is a plant from here. See, the Europeans do not grow cocoa (A. G, 69 years old, planter, L. M, 73 years old, planter).

These answers are summarized in the following table: 
Table 1. Knowledge of cocoa farming.

\begin{tabular}{|c|c|c|}
\hline $\begin{array}{ll}\text { Answers } & \text { Numbers } \\
\end{array}$ & Number of people & Pourcentage (\%) \\
\hline Knowledge & 15 & 15 \\
\hline Ignorance & 85 & 85 \\
\hline Total & 100 & 100 \\
\hline
\end{tabular}

Out of 100 respondents, about 15 farmers (15\%) know the history of cocoa farming in Côte d'Ivoire. These respondents have a level of education that oscillates between secondary and higher education. On the other hand, 85 people, the majority (85\%), who do not know this activity, are illiterate and have dropped out of school very early. Therefore, this segment of the population can not understand the message conveyed in books, sources of knowledge. If cocoa farming has a history, what is it for? To this question, the respondents replied:

With cocoa growing, our country has grown. Through this activity, we have invested on many levels. The children are in school. They are fed. When they get sick, they are taken to the clinic or hospital for care. But there is more. The sums of money we earn enable us to build modern houses, more beautiful than the huts of yesterday. Cocoa farming is emerging as the first crop in this region. Many people are involved in this activity (A. D, 46 years old, planter, P. F, 39 years old, planter).

The answers are summarized in the following table:

Table 2. Importance of cocoa farming.

\begin{tabular}{lll}
\hline \multicolumn{1}{c}{ Numbers } & Number of people & Pourcentage (\%) \\
\hline Nonswers & 0 & 0 \\
Wealth source & 100 & 100 \\
Total & 100 & 100 \\
\hline
\end{tabular}

The data reveal that $100 \%$ of respondents confirm the importance of cocoa farming. For the farmers, the activity is a source of wealth because it provides substantial income to the population. The sums of money intervene in the satisfaction of social needs (food, housing, health, schooling). Despite this importance, agricultural innovations are experiencing blockages. Why are peasants reluctant?

\subsection{Reluctance to Innovations}

We asked the people about the causes of blockages related to agricultural innovations. Here are some of the answers:

There are many problems related to innovations. The persons designated for training and supervision are not always present. We are obliged to pay the pods and certain products at exorbitant prices. In the end, our revenues are swallowed up in expenses. Some framers sell the products to us. Others choose to favor peasants, whom they know or who are close relatives (D. P, 37 years old, planter, K. L, 49 years old, planter).

The products (insecticides) used to spray the fields are danderal. Precautions must be taken to do this. Those who do not have enough money to protect themselves are exposed to diseases (skin problems, eye problems, coughs...). In the long run, they can expose themselves to emerging diseases (cancer). Also, the misuse of insecticides can negatively affect the soil. So there is little awareness. Agricultural policy (innovations) is developed without us. We are not involved. This marginalization is a real obstacle (E. L, 58 years old, planter; R. T, 43 years old, planter).

Communication does not always happen, because there are many illiterate people. The trainers and supervisors at this level encounter difficulties in getting the message across. We therefore understand that there are difficulties related to awareness. But we do what we can (H. B, 30 years old, framer).

The answers are summarized in this table:

Table 3. Obstacles related to innovations.

\begin{tabular}{lll}
\hline Answers & $\begin{array}{l}\text { Number of } \\
\text { people }\end{array}$ & $\begin{array}{l}\text { Pourcentage } \\
(\%)\end{array}$ \\
\hline At the economic and social level & 75 & 75 \\
At the environmental level & 25 & 25 \\
Total & 100 & 100 \\
\hline
\end{tabular}

Out of 100 respondents, 75 people report that there are economic and social problems when 25 farmers reveal environmental problems. The presence of difficulties related to agricultural innovations is a reality, because $100 \%$ of respondents support this thesis. In order to circumvent the situation, an analysis of the situation is necessary.

\subsection{Deconstruction of Agricultural Policy}

To remedy the situation, we interviewed the respondents, here are their answers:

We must be involved in everything, what is taken as decisions. We never come to ask ourselves the problems we encounter on a daily basis. Do we have the means to pay for the products that are available to us? The products are expensive, the material is also expensive. With our poverty situation, can we buy them. Should we also see if the products used in plantations are not dangerous? (K. P, 56 years old, planter; D. K, 63 years old, planter).

The comments of the respondents are summarized in the following table:

Table 4. Deconstruction of agricultural policy.

\begin{tabular}{lll}
\hline \multicolumn{1}{c}{ Numbers } & $\begin{array}{l}\text { Number } \\
\text { of people }\end{array}$ & $\begin{array}{l}\text { Pourcentage } \\
(\%)\end{array}$ \\
\hline Involvement of farmers in decision-making & 69 & 69 \\
Improved social relations, awareness & 31 & 31 \\
Total & 100 & 100 \\
\hline
\end{tabular}

The majority of the surveyed $69 \%$ think, that they must be associated with the decisions concerning them. Also, impact studies must be undertaken to assess the scope of modernization and productivity strategies. 31 people $(31 \%)$ believe that relations between them, supervisory agents and cooperatives are regularly conflicting. They also want good awareness to get them to take ownership of agricultural innovations. The results of the field which are articulated around three major axes were analyzed. 


\section{Discussion}

\subsection{Presentation of Cocoa Farming}

\subsubsection{History of Culture}

The literature review attests to the external origin of cocoa farming. It indicates that cocoa appeared in the Gold Coast (then Ghana) in 1871. Exports to Great Britain began in 1881. British colonization turned its attention to this activity, which was already productions, with palm oil, latex and mining productions. The production center is then located in the hinterland of the city of Accra, the current Eastem Region, which has benefited from high population densities. The planted areas are spread very rapidly spontaneously, without the intervention of the colonizer. The spread of culture is encouraged by religious missions and their botanical gardens. The expansion followed the implementation of road and rail infrastructure. It was not until about 20 years later, around 1890, that cocoa was reported in western Côte d'Ivoire, on the borders of Liberia, where it met with coffee plants. But the sparsely populated and remote region has not attracted the attention of the colonial authorities, who have given their development priorities to the Basse-Côte, around the capital, and to the east where the English rival must be contained and where, also, a timid coffee culture was experienced. It should be noted, however, that this territory, unlike Ghana, was not the object of particular economic attention by the colonizer [9]. The first real cocoa plantations, associated with coffee plantations, were created by European planters in 1895 in the Basse-Côte. Ten or so, they are unequally distributed and small areas. A few years later, pods introduced by a Fanti from the Gold Coast allowed sowing to Tiassalé, a hundred kilometers northwest of the capital. But all these plantations are established on poor soils or lowlands and, poorly maintained, they have not been slow to disappear in whole or in part [10]. In 1904, the production of the territory was 2 tons. At that time, on the other side of the border, the conquest of the plant has already reached Kumasi, in the heart of the Ashanti country. In 1908 production was 20000 tons, and three years later the country became the world's largest producer. Faced with this overwhelming success, the French colonizer reacts late and with deplorable methods. Thus, in 1912, it was decided to intensify the culture in the border circle of India, in the east of the country. But whereas in the neighbor, it appeared in the form of the native plantation wanted and favored by the colonizer, here it is initially imposed by the administration. It was part, as well as cotton, mandatory crops installed on the famous "fields of the Commander". The reluctance of farmers has materialized by the destruction of plants, by tearing or more often scalding. It took a few years, to see the powers loosen their embrace and finally offer incentive prices to promote the adoption of culture. The emergence of individual plantations is then stimulated by the arrival of migrants from the center of the country, who fled the forced crops, and from the west, driven by the many exactions of a pacification, which never ends; they saw in employment on these parcels an escape. In 1919, cocoa became one of the bases, alongside gold, and the colonial economy. In the following decade, extensions expanded westward to what was known as the cocoa loop. To the south, the colonial authorities of Côte d'Ivoire decided in 1932 to intervene to increase production. It was Governor Rest's stimulus program whose slogan was "enrich and feed the natives" [11].

On the eve of the world war, the gap in production between the two countries was still considerable $(300,000$ tons in the Gold Coast against 55,000 in Côte d'Ivoire). In terms of areas conquered by the culture, the difference was also important, since in the last country, the Bandama River was not yet reached, and the center-west, the southwest, sparsely populated, were available. Claims of the young African agricultural union (Saa), founded in 1944 and led by the future President of the Republic, Félix HouphouëtBoigny have grown. The Saa consisted of planters with at least 2 hectares of coffee and 3 hectares of cocoa, and set itself the goal of removing all the obstacles put in place by the administration: forced labor, price discrimination, compulsory deliveries, difficulties in recruiting workers. The Ghanaian erosion was the irresistible rise of Côte d'Ivoire. Cocoa became a priority in terms of agricultural policy. As early as 1971, the Ivorian State received important international financing (World Bank, European Fund) which allowed the start of a cocoa extension program entrusted to Satmaci. All of these measures have resulted in Côte d'Ivoire becoming the world's largest producer: it has surpassed Ghana since 1977. The gap widens, both with the continued fall of Ghanaian production, which fell below 200,000 tonnes in the early 1980 s, for the first time since the 1920 s, and the exponential growth of the Ivorian crop, which reached 800,000 tonnes in the late 1980s, and that lasted until 1994. The Ghanaian planter quickly perceived his new benefits nibbled; the real price to the producer has decreased since 1988. In Ivory Coast, the state tried to use its weight on the world market (one-third of production) to restore prices by retentions of exports. Houphouët-Boigny made a point of keeping the high price to the producer. The maneuver failed, and the Ivorian state was forced to cut the purchase price by half [12].

For the most part, cocoa farming is a traditional form of extensive agriculture, found in localities of the country, particularly in Boguedia. It uses limited technical means and a relatively large workforce, because of the low level of mechanization. This situation has led the country's authorities to opt for intensive farming, in order to increase productivity, and to enable the population to escape impoverishment. Intensive agriculture innovations are cultural practices, which are not part of the routine activities of cocoa farmers in the sub-prefecture of Boguedia, and which are indispensable for the intensification of crops. This is the use of the selected seeds. The plant material proposed by the National Center for Agronomic Research, consists of early hybrids "Cacao Mercedes", vigorous, high-producing and tolerant to hazards. For one hectare of plantation, 50 selected mature pods are needed, which produce about 1500 plants. These pods are 
available between October and January. It is also about irrigation. For a good plantation, irrigation is recommended, especially in Boguedia. It remains an ideal solution to no longer worry about cocoa trees, which are experienced when the dry season is very pronounced. Many cocoa trees die during this dreaded period of planters. Irrigation of plantations also ensures a good harvest every year.

We can also mention agricultural mechanization. It seduces by its ability to significantly reduce the work effort. Mechanization can make cocoa farming more rewarding and more attractive. All respondents in the locality wish the advent of this practice. Two tractors and a tiller are active in Boguedia. The peasants are admiring the passage of these machines. These machines belong to two cocoa farmers, ie $1 \%$ of the respondents. Most of the farmers (about 99\%) do not practice agricultural mechanization. This fact is explained by the exorbitant prices of these machines, which are expensive. They can not get it. There is also the use of pesticides and soil fertilization. These practices make it possible to maintain the cocoa trees, which become perennial with a very good yield. This is why all cocoa farmers are in favor of using fertilizers. Through these practices, it is the improvement of the harvests, the longevity of the cocoa trees and the reduction of the renewal efforts that are targeted by the peasants. Fertilization is perceived by the actors as an essential factor in their fulfillment to the extent that their life is intimately linked to the practice of cocoa farming. While these practices are welcomed by farmers, obstacles still remain. The above description of cocoa farming shows the importance of the activity.

\subsubsection{The Socioeconomic Value of Cocoa Farming in Boguédia}

We have indicated in the reports that cocoa cultivation is a source of wealth. This activity is essential for the population, since the work provides substantial income for producers. The data showed that out of 100 respondents, 25 people $(25 \%)$ receive between 1300000 FCFA and 1800000FCFA; 18 people $(18 \%)$ earn about 1600000FCFA and 2000000FCFA; when 9 people $(9 \%)$ receive more than 2000000FCFA per year. These incomes, which are substantial, contribute to the satisfaction of social (or physiological) needs. [13] During traditional ceremonies (bagon), religious holidays (Passover, Christmas, Ramadan, Tabaski), sums of money from the sale of cocoa are swallowed up in food, housing, clothing, health, and new homes are built from cocoa revenues.

\subsection{Obstacles to Adopting Innovations}

\subsubsection{Poverty}

The people complain about the high prices of the products and equipment available to them. This situation shows that the respondents are economic cancer patients [14], who make savings of candlesticks. This impoverishment is endemic, since it affects all the inhabitants of the country. Indeed, after the financial haemorrhage of the $1980 \mathrm{~s}$, due to poor governance, the slump of the coffee-cocoa duel, the austerities measures of the international financial institutions (World Bank, IMF), the populations in general have become impoverished. In this way, they can not afford the machines for the modernization of their plantation.

\subsubsection{Diversification of Activities and Reduction of Investments}

It means for the cocoa farmers, the exercise of several activities to increase the means of survival, multiplying the sources of income. Diversification under its two (2) aspects (agricultural and non-agricultural) is a method used by respondents to avoid reliance on a single product. It presents itself as an obstacle to the practice of intensive agriculture. In the countries where it is practiced, intensive farming is characterized by large monoculture farms. We devote the necessary time, enormous technical, material and financial resources and proven expertise, exclusively to the chosen culture. The diversification of cultures is part of a contrary approach, the available resources are crumbled and spread over several crops. This strategy does not allow effective application of innovations.

Also, uncertainty leads to caution among producers. These adopt behaviors contrary to the commitment supported, and to the large investments necessary for the use of the innovations of the intensive agriculture. In view of CNRA's "Cultivating cocoa in Côte d'Ivoire" fact sheet, we realize that cultivating cocoa from the perspective of innovations in intensive agriculture requires financial investments. This dynamic can not therefore be accommodated with the obvious desire to reduce the investments made by Boguedia's cocoa farmers. Thus, fixed capital allows the purchase of buildings (installation of a factory for example), machines and tools. Modern intensive agriculture uses modern equipment. These are agricultural machinery, used in irrigation, soil drainage, etc. It also uses seeds, fertilizer, crop maintenance products. Given the poverty, farmers are not able to afford modern farm machinery to increase production and save time.

\subsubsection{Conflictual Relations, Health and Environmental Risks}

Relational difficulties with local institutions (cooperatives) are a reality. The provisions and means required by the innovations of intensive agriculture are difficult to envisage in the individual framework of the cocoa farmer. This situation makes the cooperative an ideal instrument for promoting new technologies. The current inability to restore confidence in cocoa farmers is an obstacle that prevents the use of innovations in intensive agriculture. The position of cooperatives in the sub-prefecture of Boguédia has been penalizing in recent years. Added to this are the perverse effects of the selection principle. It is clear in the cocoa farming environment that there is no match between the plant material offered, the number of applicants and the quantity desired by each of them. In such a situation, unable to satisfy everyone, a selection is always made. The operation was carried out under conditions of approximate transparency, to the detriment of the cocoa farmers surveyed, who wanted to 
receive pods of selected seeds of "cocoa Mercedes". Those who have registered remain convinced that their names have been withdrawn for the benefit of those who are better off or closer to the chosen intermediary. This respondent argues: «We are used to that. Before the materials arrive, we take your name. But in the end, they are attributed to other people, who are close to the distributor, or who offer him more» (D. T, 50 years old, planter).

There are also the effects of corruption. Some local actors divert the opportunities offered by the programs to their own account. Initiatives favoring the use of innovations in intensive agriculture, conducted as part of the national plan for sustainable development, reform of the coffee-cocoa sector in the sub-prefecture of Boguédia, through the distribution operation Selected seed pods of "Mercedes CNRA cocoa" are undertaken. But they do not escape the principle of diversion. The intermediate agent, far from seeking a fair distribution of endowments for the development of cocoa farmers, adopts a course of action that is in his own interest. It takes a contribution to some respondents, while the distribution operation is free. This respondent confirms:

Last time in Bouafle, on TV, i twas said that good things were being done in the peasant world. Large sums of money have been announced. At home, I really do not see anything. I have the impression that the government is taking money on our behalf, and using it for other puposes (S. F, 41 years old, planter).

Among the obstacles is the search for security. New proposals, even those geared towards development, always give rise to a feeling of mistrust (security provision). We prefer to focus on what we already know. Most of the provisions of social actors in this case, aim to minimize the risks, and to trust, only to what has already proven itself. It is a work of information and awareness well conducted, which can reassure and overcome reluctance. However, the initiatives of the institutions, which aim to use the innovations of intensive agriculture, through the operation of distribution of pods of selected seeds of "cocoa Mercedes CNRA", are not the subject of sufficient information. The initiators do not raise awareness towards those concerned. These respondents support:

"This means that the government wants to help us modernize our cocoa plantations and the way we work. But we do not know, how are you going»? (G. B., 38 years old, planter).

"Nobody comes to really explain to us all these things that the government wants to do for us. It would be interesting if people come to us here to see how to help us achieve these new things» (M. S, 50 years old, planter). The low participation of beneficiaries in the design, management and monitoring of achievements is one of the difficulties encountered. The most negative consequences of the intervention strategy were, in particular, the lack of support by rural populations for monitoring and management of achievements. Ultimately, despite their cost, the initiatives taken in this register are not effective enough to reverse or halt the process of impoverishment of cocoa farmers. The poverty of the populations and the precariousness of the living conditions tend to be accentuated in the sub-prefecture of Boguédia. We do not forget the difficulties related to the effective achievement of objectives In pursuit of its objectives, the local coffee-cocoa delegation has many difficulties with cocoa farmers. One of the major difficulties in achieving a fair and equitable distribution is the lack of control over the exact number of producers due to the incompletion of the census of coffee and cocoa producers. Insufficient material support to planters and lack of financial resources for the reprofiling of product flow channels limit the scope of the Coffee and Cocoa Council's initiatives in the region. The insufficiency of quality resource persons (lack of control staff or field agent for control in the most remote areas) and the lack of readability in the management of cooperatives make the Coffee and Cocoa Council's mission in the field difficult. Health risks are certain in the work. Intensive agriculture innovations involve the use of pesticides in cocoa farming. Studies undertaken at Boguedia show the actual use of these products in plantations. The term "pesticide" includes chemicals intended to repel, destroy or control pests and undesirable species of plants or animals, causing damage to food, agricultural products, wood and wood products, or food for animals. The pesticides in question are those used to fertilize the soil and treat the plantations. A study provides insights into the use of pesticides in the cocoa sector in Cameroon [15]. A stratified sampling device is used. A total of 251 cocoa farmers, 20 post-harvest cocoa traders, and 37 chemical distributors were randomly selected and interviewed. The study showed that 35 different pesticides are marketed in Cameroon for use on cocoa. These are four herbicides, 11 fungicides and 20 insecticides. Of the 251 farmers consulted, 243 (97\%) reported using pesticides on their farm. Fungicides are the most used products by farmers $(61.8 \%)$, followed by insecticides (38.2\%). Eight pesticides (endosulfan, benomyl, propoxur, methylparathion, fenobucarb, profenofos, cartap and diazinon), although officially prohibited, are still used on cocoa farms. More than $77 \%$ of farmers do not comply with the recommended spray rates for fungicides and $50 \%$ exceed doses.

This is the case of cocoa farmers in Boguedia. Out of 100 respondents, 13 people contracted lung diseases (cough), skin conditions, eye problems and indigestion. The analysis shows the existence of a relationship between pathologies and the use of pesticides. This situation is due to the lack of practical arrangements during the work. Peasants whose educational level oscillates between illiteracy and primary level, for the most part do not control the recommendations concerning the use of products. Also, the low awareness of farmers against the harmful effects of pesticides explains the reality in this locality. Evil or uninformed, they exercised the work without maximum protection (helmet, gang). By imprudence, the farmers failed to wash their hands and bathe before feeding. These reasons led to the said pathologies in Boguedia cocoa farmers. The involvement of pesticides in diseases is justified 
by Onil [16]. According to the author, long-term use of pesticides can have effects on humans. They can cause cancer, genotoxic effects, effects on reproduction and development (malformation, reduced fertility...). The use of phyto-pharmaceutical products is a major public and environmental health issue for applicators, their families, residents and the general population. The various studies highlight significant increases in risks for several pathologies related to the exposure of workers and their families (prostate cancer, parkinson's disease, non-Hodgkin's lymphoma, multiple myeloma, central nervous system damage). Faced with the difficulties related to the adoption of innovations in cocoa farming, proposals are made.

\subsection{For a Deconstruction of Agricultural Policy}

These are recommendations to help people take ownership of cocoa plantations in Boguedia. Technology acceptance is an essential phase for Africa's development. We understand that the use of innovations in intensive agriculture requires an understanding of the relationship that the black continent has with technoscience. By tackling this issue, African intellectuals have a contradictory debate about the need for appropriation of foreign technologies. The need to clarify the relationship between Africa and Africa in Africa, before defining the ideal of this relationship in the light of the objective condition of Africa today [17].

In the general context of low resources, particularly water resources, the common point of all traditional production systems is that they aim at minimizing the financial risk in the light of climatic and economic uncertainty. Sustainability of production in systems where the environmental resource is low, certain key principles must govern the implementation of interventions. The first is that a technological innovation can only contribute to human progress if the factors of social appropriation that guarantee the ecological and economic sustainability of the production systems are correctly analyzed. It should be noted that these systems, which minimize risks abandoned in developed countries, are now regaining interest given the environmental imperative [18].

Some of these systems are promoted by local initiatives that need to be identified and supported. Another principle is that the permanent changes in the ecological, economic and human environment make it necessary to take into account the fact that the optimum of technico-economic viability is in constant displacement. Therefore, the innovation process must be part of a dynamic and reflective trajectory, where secular knowledge is often associated with expert knowledge, and where taking into account all the actors in the innovation process will guarantee it. impact and sustainability. The coupling of technical progress and social progress can only take place if there is an increase in the skills of local actors [3].

The sustainability and adaptability of technical changes can not be achieved without awareness ownership of new strategies by beneficiary populations is linked to the involvement of stakeholders in the project (design, implementation, monitoring). The use of innovations in intensive agriculture is an approach that must be justified by its effective contribution to the full development of man. Innovation for this reason must have a very pronounced social dimension [19]. The aim of social innovation is to contribute to meeting the major social issues: to reduce poverty and fight against exclusion, to protect the environment, to promote the integration of people with disabilities, to enable young people to be part of life professional and civic life, fight against unemployment, take into account the issues related to the aging of the population, contribute to the education and development of children.

\section{Conclusion}

In the context of the use of innovations in intensive agriculture, relations are established between the cocoa farmers and social structures (institutions and programs) involved in the field. Highlighting the relationships that develop between institutions carriers innovations of intensive agriculture and cocoa farmers, discloses a system plagued by malfunctions (organizational, health). These are mainly the result of poor communication, a logical contradictory actions of confrontation developed by many actors with divergent interests, involved in the process of using the innovations of intensive agriculture. The system that is established around the relationship between cocoa farmers and institutions, social and micro-meso-social level, is not conducive to the spread of new cultivation techniques in the Sub-prefecture of Boguédia. In fact, the non-application of the principles of participatory project management is the main weakness of the relations established between local structures, national institutions and farmers. Socio-economic, health and environmental problems point to the need to deconstruct innovations in cocoa farming, modernize activity and increase productivity in Boguedia

\section{Acknowledgements}

We would like to thank, very sincerely, the organizers of the American Journal of Agriculture and Forestry for the call for papers. Our infinite gratitude goes to the farmers of Boguedia and all the actors of cocoa farming, who made possible the realization of this research.

Nous tenons à remercier, très sincèrement les organisateurs de American Journal of Agriculture and Forestry pour l'appel à contribution. Notre infinie gratitude va aux planteurs de Boguedia et à tous les acteurs de la cacaoculture, qui ont rendu possible la réalisation de cette recherche.

\section{References}

[1] G. Austin (2010). Economic development and colonial legacies in Africa. International Development Policy Review 1, 11-36.

[2] D. A. N. Yedagne (2015). Social and practical representations of rubber growing in odzukru country in the region of Dabou (Ivory Coast). Bouaké, 385p. 
[3] G. B. Blegui (2018). Ivory Coast cocoa farming facing the innovations of intensive agriculture in Boguedia. Bouaké, 398p.

[4] B. Malinovsky (1922). The Argonauts of the Western Pacific. Paris, 616p.

[5] J. M. K. Kouamekan (2014). Resilience and societies: concepts and applications. Ethical and economic 11 (1), 28p.

[6] D. Pruit (2010). Conflict and negotiation: half a century of research in social psychology. Negotiation 1 (13), 99-113.

[7] A. Mullenbach (2007). The contribution of stakeholder theory to the modeling of corporate social responsibility. Journal of Management Science 1 (223), 109-120.

[8] E. Poulain (2001). Human capital, from a substantial conception to a representational model. Economic Review 52 (1), 91-116.

[9] E. H. Freud (2000). The fields of cocoa. An Africa-Asia competitiveness challenge. Paris, $210 \mathrm{p}$.

[10] J. Burle, (1952). Cocoa production in AOF. Bingerville, Agricultural Research Center, 304p.

[11] J. Ibo, (1997). Prejudices and Realities of the Colonial Legacy of Ivorian Agricultural Policy: The Economic Program of the Dieudonné Government Rest of Rocca. Bulletin of Gidis 15, Petit Bassam, 81-97.
[12] J. L. Gombeaud, S. Smith (1990). The cocoa war, a secret history of an embargo. Paris, 218p.

[13] A. H. Maslow (1943). A Theory of Human Motivation. Psychological Review 50, 370-396.

[14] D. Moustapha (1999). The capability indicamétry. Bouake, $14 \mathrm{p}$.

[15] R. Mahob, L. Dibog (2012). Use of pesticides in the cocoa sector in Cameroon: Characterization of the means of supply, the nature, manner and reasons for their use, 17th International Conference on Cocoa Research. Yaoundé, p302.

[16] S. Onil (2014). Agricultural pesticides: impact on human health and the environment. Quebec, 41p.

[17] L. Ayissi (2006). An attempt to clarify Africa's report to technoscience. Annals of the Faculty of Arts, Letters and Human Sciences of the University of Yaoundé 1 (4), 113-133.

[18] L. Chavassus (2007). A new modernity: a productive agriculture with ecological value, Economy and agricultural strategies. Paris, 7-48.

[19] C. Patureau (2010). Innovate to meet social needs. Professional Thesis. Paris, 9p. 